\title{
The Research on the Public Policy of Carbon Reduction Power Industry of Inner Mongolia
}

\author{
Song Fang \\ Inner Mongolia University of Technology \\ School of International Business \\ Hohhot, China \\ 553187601@qq.com
}

\author{
Ma Jun* \\ Inner Mongolia University of Technology \\ School of International Business \\ Hohhot, China \\ majun@imut.edu.cn \\ * Corresponding Author
}

\begin{abstract}
Power industry is not only the economic development of the most important basic energy industry, but also the largest carbon emission sectors of the industry. As an energy consumption and pollution emissions province, Inner Mongolia power industry is the focus of energy saving industry, thus promoting the electric power industry to carry out carbon dioxide emissions, is an important positive practice of low-carbon development strategies in the proposed region. Based on the analysis of current situation in Inner Mongolia power industry carbon emissions, this paper analyzes the industrial structure and carbon emissions trading problems in the Inner Mongolia Electric Power Industry, and finds the path to energy conservation, so that internal and external power system may cut emissions proposals to make better and faster development of Inner Mongolia Electric Power on the road of green electricity.
\end{abstract}

Keywords- Carbon Emissions; Power Industry; Public Policy; Carbon Emissions Trading; Green Power

Power industry is the basic industry of the national economy, and its development and economic development are closely related. With the booming economy and society in Inner Mongolia, Inner Mongolia Electric Power has been an unprecedented development on the basis of its location and resources, the region has made an irreplaceable contribution to the economic and social development of Beijing and Tianjin. However, under the current environmental problems, apparent contradictions between economic development and resources and the environment have become increasingly prominent, and the sustainable development of Inner Mongolia Electric Power is facing severe challenges. Based on the analysis of current situation in Inner Mongolia power industry carbon emissions, this paper analyzes the industrial structure and carbon emissions trading problems in the Inner Mongolia Electric Power Industry, and finds the path to energy conservation, so that internal and external power system may cut emissions proposals to implement the Inner Mongolia "8337" development ideas, which is an opportunity to open up the road of sustainable development in Inner Mongolia power.

\section{SitUATIONIN INNER MONGOLIA ELECTRIC POWER INDUSTRY AND CARBON EMISSIONS ANALYSIS} A. Inner Mongolia Electric Power Industry
Development Status

1) Inner Mongolia Electric Power Industry Basic profile

By 2014, annual generating capacity of Inner Mongolia Power Grid have completed 212.348 billion kwh, an increase of $7.19 \%$ over the previous year; installed capacity of 51.07 million kilowatts, an increase of $9.34 \%$. Annual electricity sales have completed 145.764 billion kwh, an increase $5.10 \%$ over the previous year, the annual plan of 109.6\%; complete line loss rate $4.29 \%, 0.13$ percentage points lower than the same period last year, 0.39 percentage points lower than the annual plan; total completed 183.16 billion kwh electricity consumption, an increase of $8.94 \%$ over the previous year. Inner Mongolia Power Grid 2004--2013 annual sales power in Table I.

TABLE I. INNER MONGOLIA POWER GRID 2004--2013 ANNUAL SALES ELECTRICITY SITUATION

\begin{tabular}{ccc}
\hline Year & $\begin{array}{c}\text { Utilization } \\
\text { hours(hours) }\end{array}$ & $\begin{array}{c}\text { Eectricity sales (one } \\
\text { hundred million kwh) }\end{array}$ \\
\hline 2004 & 7421 & 458.95 \\
2005 & 7010 & 594.58 \\
2006 & 6406 & 808.04 \\
2007 & 5370 & 1089.57 \\
2008 & 4435 & 1203.16 \\
2009 & 4115 & 1257 \\
2010 & 4219 & 1283 \\
2011 & 4367 & 1752 \\
2012 & 4405 & 1820 \\
2013 & 4472 & 1981 \\
\hline
\end{tabular}

Source: Internal Inner Mongolia Power (Group) Co.,Ltd. Profile

\section{2) Inner Mongolia Power Grid "west to east" situation}

Inner Mongolia is rich in coal resources, are key areas "west to east" strategic project. Inner Mongolia net "coal away from the air, power transmission Beijing," the West 
to East strategy began in 1989, when the Inner Mongolia Power Grid to Datong by Fengzhen 220 kV double-circuit transmission line to the North China Power Network. As of 2009, Inner Mongolia, from West to East strategy 20 years, total consumption reached 133.84 billion kwh-East. Year 2010, Inner Mongolia, North China Power Grid electricity transmission grid to 27.115 billion $\mathrm{kwh}$, an increase of 2 times more than in 2005. Inner Mongolia Power Grid 2001--2013 -East power changes are shown in Fig. 1.

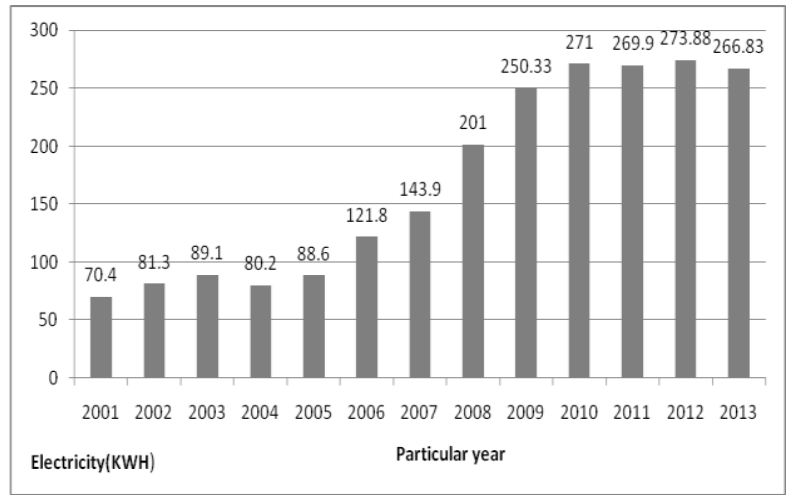

Figure 1. Inner Mongolia Power Figure from 2001 to 2013 -East power change map

Source: Internal Inner Mongolia Power (Group) Co.,Ltd. Profile

\section{B. Situation in Inner Mongolia typical power plant} emissions analysis

\section{1) Inner Mongolia Jing long power plant}

Jinglong Power Plant in Inner Mongolia, Beijing Energy Investment (Group) Co., Ltd., China Huadian Corporation, and Inner Mongolia Huaneng Thermal Power Co., Ltd. jointly funded the construction, investment in construction of the "HSBC, three" project, covering $75.1587 \mathrm{hm} 2$, Project static investment of 4.8456 billion Yuan, dynamic investment 5,112,680,000 Yuan, the construction of two $2 \times 600 \mathrm{MW}$ air-cooling units, unit selection: subcritical coal-fired air-cooled. Projects in environmental protection and efficient use electrostatic precipitators and urban water recycling technology, its smoke emission concentration can meet the "thermal power plant air pollutant emis sion standards", the project is sent to the Tianjin-Tangshan power grid, has been Inner Mongolia Autonomous Region development and Reform Commission included in the "North China Power Grid," Eleventh five-Year "power plan" is to protect the Beijing 2008 Olympic Games, and solve an important power base of the future electricity Tianjin-Tangshan region for the development of electricity. The plant is to ensure stability in West Inner Mongolia grid capacity from West to East, which has a very important position. Through research, researchers learned the power generation and coal burning plant is shown in Table 2 and Table 3.

TABLE II. 2012--2014 INNER MONGOLIA JINGLONG POWER INDICATOR POWER GENERATION COMPANY LIMITED

\begin{tabular}{ccccccc}
\hline Year & $\begin{array}{c}\text { Eectricity } \\
\text { (MWh) }\end{array}$ & $\begin{array}{c}\text { Power } \\
\text { consumption(MWh } \\
\text { ) }\end{array}$ & $\begin{array}{c}\text { Main transformer } \\
\text { high side } \\
\text { power(MWh) }\end{array}$ & $\begin{array}{c}\text { Eectricity } \\
\text { sales(MWh) }\end{array}$ & $\begin{array}{c}\text { Jing Feng I, } \\
\text { II line }\end{array}$ & $\begin{array}{c}\text { Settlement grid } \\
\text { electricity }\end{array}$ \\
\hline 2012 & 6780919.57 & 526071.74 & 6247013.71 & 6249580.41 & 6249580.4 & 3915368.361 \\
2013 & 7439540.78 & 585237.74 & 6844598.53 & 6846217.1 & 6846217.1 & 4200664.761 \\
2014 & 7301333.28 & 576605.24 & 6711687.48 & 6715536.9 & 6715536.9 & 4529834.561 \\
\hline
\end{tabular}

Source: Field research in Inner Mongolia Jinglong Generation Co., Ltd.

TABLE III. 2012--2013 INNER MONGOLIA JINGLONG POWER GENERATION COMPANY LIMITED AMOUNT OF COAL FOR POWER GENERATION

\begin{tabular}{ccccc}
\hline Year & $\begin{array}{c}\text { The average calorific value of } \\
\text { coal into the furnace }(\mathbf{K J} / \mathbf{K g})\end{array}$ & $\begin{array}{c}\text { Off coal } \\
\text { coal (tons) }\end{array}$ & $\begin{array}{c}\text { Oil off of standardcoal } \\
\text { (tons) }\end{array}$ & $\begin{array}{c}\text { Generating coal } \\
\text { (tons) }\end{array}$ \\
\hline 2012 & 16976.63 & 2132563.89 & 304.97 & 2132868.86 \\
2013 & 16452.25 & 2332189.02 & 77.13 & 2332266.15 \\
\hline
\end{tabular}

Source: Field research in Inner Mongolia Jinglong Generation Co., Ltd.

2) Jin shan Hohhot Power Plant

TABLE IV. CARBON EMISSIONS FROM POWER PLANTS JINSHAN STATISTICS

\begin{tabular}{|c|c|c|c|c|c|c|}
\hline Year & $\begin{array}{c}\text { Coal-fired } \\
\text { generating heat } \\
\text { (tons) } \\
\end{array}$ & $\begin{array}{c}\text { Carbon } \\
\text { content of coal- } \\
\text { fired }(\%) \\
\end{array}$ & $\begin{array}{c}\text { Mass fraction } \\
\text { of carbon in fly } \\
\operatorname{ash}(\%) \\
\end{array}$ & $\begin{array}{c}\text { Carbon } \\
\text { content of } \\
\text { slag }(\%) \\
\end{array}$ & $\begin{array}{c}\text { Carbon } \\
\text { emissions(to } \\
\text { ns) } \\
\end{array}$ & $\begin{array}{c}\mathrm{CO2} \\
\text { emissions (tons) }\end{array}$ \\
\hline 2010 & 826214 & 48.46 & 3.11 & 2.44 & 354528 & 1299936 \\
\hline 2011 & 1408812 & 45.91 & 3.02 & 1.81 & 578740 & 2122047 \\
\hline 2012 & 1523372 & 45.33 & 2.69 & 1.77 & 622602 & 2282874 \\
\hline 2014 & 1384169 & 17.12 & 2.57 & 1.27 & 599068 & 2196583 \\
\hline
\end{tabular}

Source: Based on data research computing finishing plants Jinshan Hohhot 
Jinshan Hohhot plant through to conduct research, communicate with technical staff and management of the plant, researchers got the plant nearly five years the number of fossil fuel use, air quality and carbon dioxide emissions. With these data, researchers can see that the higher emissions of carbon dioxide, indicating that the power industry carbon emissions are essential (see Table 4).

\section{INNER MONGOLIA POWER INDUST RY CARBON EMISSIONS PROBLEMS}

In recent years, Inner Mongolia economic growth and energy consumption and environmental pollution to a higher proportion of value, mainly through their exhibits high input, high energy consumption and smaller income characteristics ${ }^{[1]}$. So at the expense of resources and the environment at the expense of economic development, so that the Inner Mongolia region in the future path of development must come up with a lot of energy to manage and resolve environmental problems arising at this stage. Fossil energy as the main fuel power industry is an important industry in Inner Mongolia at the present stage of economic development, the current national $85 \%$ of carbon dioxide, 90 percent of sulfur dioxide and 73 percent of soot emissions are from coal combustion. With the improvement of the development of heavy industry and the economic growth and the living standards of people in the region, regional energy consumption for electricity will continue to grow, which makes the power industry in taking the road of sustainable development encounter many problems.

\section{A. Power industrydevelopment and carbon reduction issues}

\section{1) Increasing electricity demand and reduce carbon emissions contradictory goals}

TABLE V. INNER MONGOLIA 2000--2011 COAL CONSUMPTION AND COAL POWER GENERATIONCAPACITY

\begin{tabular}{cccc}
\hline Year & $\begin{array}{c}\text { Coal consumption } \\
(\mathbf{1 0 , 0 0 0} \text { tons })\end{array}$ & $\begin{array}{c}\text { Coal power } \\
\text { generation capacity } \\
(\mathbf{1 0 , 0 0 0} \text { tons })\end{array}$ & $\begin{array}{c}\text { The proportion } \\
\text { of coal for power } \\
\text { generation(\%) }\end{array}$ \\
\hline 2000 & 5897.99 & 2566.34 & 44.7 \\
2001 & 6235.44 & 2923.64 & 47.8 \\
2002 & 6844.21 & 3218.15 & 47.4 \\
2003 & 8373.06 & 3949.32 & 47.2 \\
2004 & 11791.11 & 5732.14 & 48.6 \\
2005 & 13954.12 & 7022.23 & 50.3 \\
2006 & 16010.45 & 8465.82 & 52.8 \\
2007 & 18607.56 & 10482.82 & 56.3 \\
2008 & 22242.34 & 12674.02 & 56.9 \\
2009 & 24047.92 & 12743.26 & 56.5 \\
2010 & 27004.36 & 14992.28 & 55.1 \\
2011 & 34684.57 & 19186.31 & 55.3 \\
\hline
\end{tabular}

Source: "Inner Mongolia Statistical Yearbook (2012)

As one of the important areas of Inner Mongolia, China's economic growth, resource is mainly in the coal demand respect. As an energy province's energy mix, the Inner Mongolia is mainly dependent on coal, power generation, coal accounts for the proportion of $78 \%$. Among them, especially the power industry, as a resource-intensive industry, the power industry's demand for coal is particular. This directly leads to an increase in carbon emissions, resulting in a double pressure on resources and the environment. Inner Mongolia 2000--2011 coal consumption and coal for power generation is shown in Table 5 .

According to the data researchers can see two aspects. First, at the expense of sacrificing the environment pulled GDP. For rigid carbon emission targets different areas required by the government, individual power companies will be forced to wind up controlling electricity [1]. Currently regional governments to improve regional GDP mainly the pressure, resulting in economic growth by a large number of carbon emissions achieved inefficiencies. Second, increase the power of contradictions and the development of carbon emissions carbon emissions market between increased. With the continuous development of the regional economy, increasing demand for electricity, which resulted in the reduction of carbon emissions and increasing power demand contradiction.

\section{2) Unequal distribution of resources limits the power system to reduce carbon emissions}

First, the uneven distribution of resources, resulting in the power industry production methods, produces different carbon emissions. As far as China's current situation is concerned, $80 \%$ of carbon reserves concentrated in the western and northwestern China. As a typical northwestern region, Inner Mongolia's the carbon demand is dominant. Many power companies reduce the cost of coal transportation mass transit from the west region, and change to hydro power and other power generation methods. However, due to production technology, October 2010 have accounted for 82.09 percent of the total water resources in the western and north-west have been developed, which can be accounted for only $9.25 \%$ utilization rate, and most of the water resources are wasted.

Second, the different power modes of production in different regions of the carbon emis sions impact. Due to the special nature of the power industry, its dependence resources are obvious. Different characteristics of different distribution of resources also caused power enterprises in different regions of the uneven distribution characteristics. Since economic development is restricted on carbon emissions trading rights aspect, in the Inner Mongolia region in the inland emissions trading scheme has also been greatly restricted, which to some degree sprain of the Inner Mongolia business enthusiasmto control carbon emissions .

\section{3) The low degree of market power industry restrictions on carbon emissions}

First, electricity prices in Inner Mongolia at the present stage of unified regulations by the government, enterprises cannot be adjusted according to changes in the market price of electricity. However, the production of electricity by the system as the main way to coal, coal prices are based on changes in the market changes occur. This makes the power industry in these areas become very passive. Corporate profits will be greatly affected, companies do not have extra money allocated to the 
problem to improve technology, control on carbon emissions. This leads companies have made similar "plan electricity market coal" decision. This way it can reduce the loss of business to a certain extent.

Second, the low market power industry will limit the development of the industry carbon emissions mechanisms. As coal-based electricity productionintensive industries, the costs of carbon emissions compared to other industries in terms of lower costs and this makes a lot of carbon emissions trading schemes are concentrated in the power industry, and because of the power industry has certain government monopoly, the market changes will not produce a very significant impact on him. Thus, addition of the coal market and other production factors generate price changes, the power system will not be affected, largely reducing the electric power enterprises to participate in carbon emissions trading system, the enthusiasm, will potentially increase carbon companies in the market action emis sions.

\section{B. Power industry carbon emissions trading Problems}

\section{1) Lack of a clear policy on carbon emissions as defined in}

The United States and other developed countries, through the "Clean Air Act" and other relevant laws to make specific provisions for emissions trading rights. In China, basically a blank state, two sessions in 2015 to make a new "air pollution prevention and control hair," the implementation of just relying on the previous "Atmospheric Pollution Prevention Act," some of the pollutants emission permit makes provision. Due to lack of the legal aspects of the country, these measures fundamental lack of technical guidance, failed to establish a unified standard. These problems make it appear to dispute the decision in terms of problems. Restricting the development of carbon emissions trading scheme, it is not conducive to control on carbon emissions.

\section{2) The initial allocation based on chaos}

Electric power industry, among the power production, power generation type and region are internationally recognized as the standard initial allocation. Ho wever, in most of the Chinese companies, any course voluntary mechanism is at the implementation stage. Inner Mongolia is one of the typical Midwestern cities, which is obviously influenced by the economy and the environment most power systems for the small thermal power units, and produces carbon emis sions as well.

Along with the growing emphasis on the carbon market, many large companies recognize the added inevitable trend of emissions trading mechanism, so in order to enhance their self-interest for the enterprise market through its own influence to influence government initially in carbon emissions decisionmaking in the allocation criteria, resulting in "rentseeking" the problem [1]. Thereby impeding the promotion and implementation of the emissions trading mechanism

3) Not form an effective tradable carbon credits
Carbon emissions through energy savings and emission reduction is a major component of the carbon quotas. However, at this stage, the relevant aspects of the technology in Inner Mongolia is still relatively weak, not able to accurately calculate and provide technology and equipment for corporate carbon emissions. These problems have a direct impact on the regulatory authorities to grasp the real situation of the relevant companies. These enterprises have a more direct benefit from this practice, and the consequent loss of the carbon emission reduction technologies to improve the initiative. Hinder the establishment and operation of carbon reduction mechanis m.

4) Existing trading platform failed to give full play to the role of

Compared with many developed countries stringent emissions mechanisms. Our carbon emissions trading mechanism has not really play its role. Local features more obvious. A direct result of the low degree of carbon market, reducing the efficiency of its two main reasons: first, there is no region in the total control system for the specific circumstances; and second, the current area of several large power generation groups in the government hard It requires carbon emissions stages of an internal carbon emissions trading, which makes it possible to trade quotas reduced carbon emissions trading program and scale of change. ${ }^{[2]}$

\section{INNER MONGOLIA ELECTRIC POWER INDUSTRY RECOMMENDED THAT CARBON REDUCTION}

\section{A. Direct emissions within the system}

1) The establishment of the power system of special carbon emissions trading platform

The establishment of the power system of special carbon emissions trading platform in order to reduce mitigation costs, capital and resources in order to promote exchanges of eastern and western regions between regional issues effectively alleviate the discrepancy between endowment and level of economic development resources, making the power system of carbon reduction row reasonable cost-sharing in the country.

(1) Conduct a comprehensive self-examination, the implementation of carbon investigation. Carbon investigation here is the bottom-up from the finer the preparation of inventories of greenhouse gas emissions and monitoring, to Figure out the number of enterprises in production and other activities directly or indirectly emis sions of carbon dioxide, emissions have much, what method to accurately measure, depending on what index more scientific grant quotas, after payment of the quota, how can tracking and monitoring and so on. For the establishment of a fair amount of monitoring and carbon emissions quota system, you first need to have a comprehensive, complete and reliable basic data, but also records positive business energy conservation and its effectiveness, to lay the foundation for a just dis tribution of carbon emission quotas.

(2) In-depth study and learn conservation methods. It is understood that the "voluntary greenhouse gas emissions trading Interim Measures," the National 
Development and Reform Commission promulgated regulations, all those involved in voluntary emissions trading program, the validation and for the record, are required to adopt national authorities (NDRC, the same below) Accreditation methodology. Another method belongs to the distribution system of science, namely how to set the amount of control and distribution of carbon emission quotas, also need to be reviewed. Because there is total control, only the value of carbon emissions, making it the commodity trade. Thus, total control is the implementation of the power industry carbon emissions trading premise. Inner Mongolia is the country's major energy base, in recent years, coal-toelectricity, coal to oil, coal-gas and other industries developed rapidly, but their output is clean energy.

(3) To develop and standardize the relevant professional intermediaries. Power sector carbon trading requires the participation of multiple agencies and professional requirements of the agency, researchers have to go through a rigorous standard of professional training. Key has certified agencies, financial institutions, information services and related industry associations four categories intermediaries. Wherein the certifying bodies is a key institution to implement major monitoring and verification of carbon trading projects, subject to the national authorities for the record. The subject matter of carbon trading - the emissions are a virtual as set has its credit value, and therefore the carbon trading market is essentially a financial market. Through trade associations cohesion within the electric power system-related businesses, the establishment of joint negotiation mechanisms to reduce electricity disorderly vicious competition among enterprises, in Inner Mongolia absolute advantage in overall carbon emissions, the impact on the Inner Mongolia Electric Power Industry market pricing of carbon emissions regulation.

(4) Related comprehensive talent shortage, strengthen the core training of qualified personnel. The State Council issued the "" five "work program to control greenhouse gas emissions," clearly states: "Strengthening the capacity to develop statistical accounting of greenhouse gas emissions responsible for full-time work force and basic statistics ranks" "Strengthening of qualified personnel to strengthen the response. Climate change education and training, be included in national education and training system, improve the relevant disciplinary system. Vigorous efforts to respond to climate change science popularization strengthen basic research to address climate change and research and development team, strategy and policy team of experts, international negotiation team of professionals and low developing carbon market services of qualified personnel. "[3]

\section{2) Change the development model, innovative "green coal" to improve efficiency in the use of coal}

Inner Mongolia coal-dominated energy structure, in order to "rich coal, less gas, lack of oil," the natural resources as the main feature. It is calculated that each ton of carbon dioxide combustion gas than burning coal will produce more oil and natural gas per tonne of three percent and Qi Cheng. Therefore, the development of "green coal" is imperative. The so-called "green coal" technology is to integrated gasification combined cycle (IGCC) and carbon capture and storage (CCS) technology as the basis, combined cycle electric power generation, and the recycling of pollutants, carbon dioxide separation, use or storage of a new coal power generation technology. One of its aims is to meet the overall demand for electricity to build and protect the atmospheric carbon balance of coal development of institutional mechanis ms.

To improve efficiency in the use of coal, should prepare the following: (1) policies. Green coal technology in China is an emerging technology, the complexity of their own is higher than existing conventional coal-fired power generation technology. Therefore, power generation enterprises in promoting early next great development potential of emerging technologies, to bear considerable risks, and therefore state support policies related industries also crucial. Because China on IGCC and CCS technology is still a lack of clear industrial policy support, making the process of implementation of "green coal" program as a whole lagged behind expectations, and there is some uncertainty. (2) Plant. Since the IGCC and CCS technology is still in the demonstration stage, has not yet started commercial promotion, relevant new technologies and new techniques in the development stage of the cumulative costs lead to "green coal" demonstration plants require high capital investment in early stage technology. So, drawing national development "green coal" technology, the progressive introduction of technological innovation throughout the entire system of power is always carbon reduction process. (3) Multi-generation, strengthen cross-sector and inter-regional cooperation. By strengthening oil means to achieve carbon sequestration, which compared to a simple direct sequestration, can bring greater benefits to the oil companies, which have more economic driving force. To promote CHP, CCHP and thermal coal gas multiple supply.

\section{3) The use of carbon transactions DSM}

Structural reduction of power consumption cannot ignore indirect carbon emissions, appropriate management of electricity demand, such as the implementation of the price ladder, to help optimize the allocation of resources, carbon emissions, reduce the total cost of the whole society electricity emissions ${ }^{[4]}$.

\section{B. Indirect emissions outside the system}

\section{1) The development of green electricity industry} road

New energy is the earth's most precious resource, integrated scheduling of new energy power generation and fossil fuel power generation is the sound development of new energy fundamental way. China accounted for more than half of the land in the northwest region has a unique advantage of the new energy resources development and congenital conditions. Such as Inner Mongolia wind power capacity of 890 million kilowatts can be developed, and the electricity sent out a short distance, low overall costs, how to make better use 
of its advantages, the comprehensive development of low-carbon energy plays an important role in promoting.

The development of green electricity from non-coal product or find a substitute for the relevant departure, high-carbon transformation of economic development mode, adjust the energy structure, vigorously develop renewable energy, promote the development of the power industry evolution towards green electricity from green coal. (1) a selective advantage of geographical location, the construction of hydropower energy base. From the existing development conditions, the hydroelectric power has great room for development, can become the main alternative to achieve coal. (2) To explore non-hydro renewable energy generation. Including solar power, wind power, geothermal power and biomass power generation. Other renewable energy power generation will undoubtedly become an important supplement to achieve coal substitute.

According to "China Electric Power Research 2014 emissions," released in 2013, the national electricity full aperture 5.3721 trillion $\mathrm{kwh}$, an increase of $7.73 \%$ over the previous year. Among them, the hydropower 892.1 billion kwh, compared with $4.27 \%$ the previous year, accounting for $16.61 \%$ of the total electricity generation; thermal power 4.2216 trillion $\mathrm{kwh}$, an increase of $7.54 \%$ over the previous year, accounting for $78.58 \%$ of the total electricity generation; nuclear power 111.5 billion kilowatts when, accounting for $2.08 \%$ of the total electricity generation; 2.57 percent of wind power 138.3 billion kwh, accounting for the total electricity generation; $0.16 \%$ solar 8.4 billion $\mathrm{kwh}$, accounting for the total electricity generation. According to FIG.

2) Advantage of resources, increase wind resources in Inner Mongolia into use

According to statistics, Inner Mongolia Autonomous Region theory can be developed reserves of 786.89 million kilowatts of wind energy, wind power can be developed reserves of 61.8 million kilowatts, accounting for $24.4 \%$ of the total wind energy reserves in the provinces first. Among them, the theory of the central and western regions can be developed reserves of 643.76 million kilowatts of wind energy, and wind energy technology can be developed reserves of 50.56 million kilowatts. Northeast theory can be developed reserves of 143.13 million kilowatts of wind energy, and wind energy technology can be developed reserves of 11.24 million kilowatts.

In recent years, the rapid development of green energy industry in Inner Mongolia is rapidly becoming a new economic growth point. A wind farm was established in 1996 in Inner Mongolia Huitengxile, China's first registered CDM project known to the world. Huitengxile wind power plant is Asia's largest wind farm, located in the Inner Mongolia Plateau, the high altitude, but also a vent, and wind resources are very rich where the annual average wind speed $10 \mathrm{~m}$ height $7.2 \mathrm{~m} / \mathrm{s}, 40$ $\mathrm{m}$ height of the annual average wind speed $8.8 \mathrm{~m} / \mathrm{s}$, wind power density of $662 \mathrm{~W} / \mathrm{m}$, the average air density of $1.07 \mathrm{~kg} / \mathrm{m}, 10 \mathrm{~m}$ height and $40 \mathrm{~m}$ highly effective wind $5-25 \mathrm{~m} / \mathrm{s}$ hours for 6255 hours -7293 hours . With strong stability, continuity is good, wind and high quality, is the ideal place to build a wind farm. Inner Mongolia Long Yuan Wind Power Development Co., Ltd. and the Government of the Netherlands to enter into this project, to 5.4 euro / ton of carbon dioxide prices for 10 years (2005-2014) reductions, opened a wind power generation emissions trading precedent in our region, demonstrating use wind resources to achieve carbon reduction feasibility and operability.

Inner Mongolia Electric Power Industry Association data show that: At present, Inner Mongolia wind power installed capacity of 7,308,900 kilowatts, and the region's wind power installed capacity has exceeded $100 \%$ for six consecutive years of growth, wind power installed capacity accounted for $1 /$ about 3 , and a breakthrough has been achieved ahead of schedule in 2010 and the beginning of wind power installed capacity reached 7,000,000 kilowatts of planning objectives, the installed capacity ranks first in the country. Currently, short-term, medium-term and long-term development of wind power and channel plan have sent Inner Mongolia to develop the full argument, fully meet the wind better and faster development. Inner Mongolia is the country's major electric power base and delivery of electricity in the nation, which will certainly continue in the future development of wind power ${ }^{[4]}$.

\section{ACKNOWLEDGEMENT}

This research was financially supported by the Natural Science Foundation of China (71363039).

\section{REFERENCE}

[1] Jiangcheng Yao. Impeding the establishment of China's carbon emissions trading system in the electricity industry research [D]. China University of Science and Technology, 2014.

[2] Tian Yanxiu Chinese electricity carbon emissions trading system research [D]. Southwest University of Finance and Economics, 2012.

[3] Liang-carbon economy to promote economic restructuring, Inner Mongolia - Interview with President of Development Research Institute of Inner Mongolia carbon Xu Bainian [J] Northern Economic.2012(Z1):.8-10.

[4] Wang, Guan Wanxiang, high Guiying development of Inner Mongolia Electric Power's low-carbon economy trend [J] Power Economic Research .2010 (16): 242-244.

[5] Han Caihong Electricity Reform Process Research [D] sustainable development in Inner Mongolia Power. Inner Mongolia University, 2014.

[6] Qin Xiaodong. Inner Mongolia Power Management System Reform of [D]. Inner Mongolia University, 2014.

[7] Pan Xiaodan. Research on the power structure optimization in Inner Mongolia based on constraint of energy conservation and emissions reduction[D]. North China Electric Power University, 2014.

[8] Tian Yanxiu. Carbon emissions trading system of China's power industry [D]. Southwest University of Finance and Economics, 2012.

[9] Xiao Jing. Development of low-carbon power industry environmental policy [D].Shaanxi Normal University, 2013.

[10] wearing climbing, Zoujia Yong, Tian Jie. Comprehensive optimization of China's power industry carbon emissions [J]. Electric Power Systems, 2013 (14) 